\title{
DO CONSUMO AO DESCARTE DE PRODUTOS E EMBALAGENS: ESTAMOS ALIENADOS?
}

\author{
FROM CONSUMPTION TO DISPOSAL OF \\ PRODUCTS AND PACKAGING: \\ ARE WE ALIENATED?
}

\author{
Recebido 21/08/2012 \\ Aceito 24/01/2013 \\ Luis Felipe Machado do Nascimento ${ }^{1}$ \\ Marcelo Trevisan ${ }^{2}$ \\ Paola Schmitt Figueiró ${ }^{3}$ \\ Marilia Bonzanini Bossle ${ }^{4}$
}

\section{RESUMO}

O termo "alienação" é usado em análises sociológicas dos sistemas produtivos (alienação no trabalho) e, recentemente, em estudos sobre consumo compulsivo. Não se identificou, entretanto, definição ou investigações discutindo "alienação no descarte" de produtos e embalagens. Nesse contexto, o intuito deste artigo é identificar a percepção das pessoas sobre implicações do ato de descartar um produto ou uma embalagem. Para isso, realizaram-se entrevistas com cidadãos e especialistas na área socioambiental em Porto Alegre, Brasil, mediante roteiros semiestruturados, abordando questões gerais sobre meio ambiente, comportamento de compra, hábitos e atitudes relacionados ao descarte e destino de produtos e embalagens. Os resultados apontam uma falta de conhecimento sobre o ciclo de vida das embalagens e dos produtos. O consumidor, durante a compra, não leva em conta que deverá descartar a embalagem e, posteriormente, o produto. O descarte é associado ao ato de "fazer sumir da frente dos olhos", sendo visto como uma atribuição dos órgãos de limpeza urbana, eximindo, assim, o consumidor de qualquer responsabilidade sobre as etapas posteriores ao descarte. Os resultados desta investigação poderão subsidiar iniciativas à conscientização socioambiental da população, bem como à elaboração de políticas para informações sobre produtos e responsabilidades dos consumidores.

Palavras-chave: consumo, alienação, descarte, consciência ambiental.

\footnotetext{
${ }^{1}$ Possui graduação em Engenharia Elétrica e mestrado em Engenharia de Produção pela Universidade Federal de Santa Maria - UFSM e doutorado em Economia e Meio Ambiente pela Universität Gesamthochschule Kassel - Alemanha e pós doutorado na University of Massachusetts - Estados Unidos. Atualmente é professor associado na Universidade Federal do Rio Grande do Sul - UFRGS. Porto Alegre, Rio Grande do Sul, Brasil. E-mail: nascimentolf@gmail.com.

2 Possui graduação em Administração pela Universidade Federal de Santa Maria - UFSM, mestrado em Administração pela Universidade Federal de Santa Catarina - UFSC e doutorado em Administração pela Universidade Federal do Rio Grande do Sul UFRGS. Atualmente é professor adjunto da Universidade Federal de Santa Maria - UFSM. Santa Maria, Rio Grande do Sul, Brasil. E-mail: marcelotrevisan@smail.ufsm.br.

${ }^{3}$ Possui graduação em Administração pela Universidade Federal de Santa Maria - UFSM, mestrado em Administração pela Universidade Federal do Rio Grande do Sul - UFRGS. Atualmente é doutoranda em Administração na Universidade Federal do Rio Grande do Sul - UFRGS. Porto Alegre, Rio Grande do Sul, Brasil. E-mail: paolaadm@gmail.com.

${ }^{4}$ Possui graduação e mestrado em Administração pela Universidade Federal do Rio Grande do Sul - UFRGS. Atualmente é doutoranda em Administração na Universidade Federal do Rio Grande do Sul - UFGRS. Porto Alegre, Rio Grande do Sul, Brasil. E-mail: mariliabossle@gmail.com.
} 


\section{ABSTRACT}

The term "alienation" is used in sociological analysis of production systems and, recently, in studies of compulsive consumption. There are no definitions or investigations discussing "alienation of disposal" of products and packaging. Following this line of thought, the aim of this article is to identify people's perceptions about the implications of the act of discarding a product or packaging. Interviews were conducted with citizens and experts in environmental issues in Porto Alegre, Brazil. We followed a semi-structured script addressing general issues about the environment, buying behavior, habits and attitudes related to disposal and destination of products and packaging. The results indicate the absence of environmental education and knowledge of the life cycle of products. The consumer, when buying a product, does not envisage that will have to discard the packaging. The disposal is associated with the act of "making disappear out of his eyes" without knowing the steps taken by the waste until its final destination. It was found detachment or alienation concerning the disposal of products and packaging. The results of this research will support initiatives to increase environmental awareness of the population, as well as to elaborate policies about product information and consumer responsibilities.

Keywords: consumption, alienation, disposal, environmental awareness.

\section{INTRODUÇÃO}

A cidade de Porto Alegre, localizada no Sul do Brasil, é conhecida pelo pioneirismo na implantação da coleta seletiva e está entre os municípios mais arborizados do mundo, com mais de um milhão e 300 mil árvores, 616 praças urbanizadas, três reservas biológicas, nove parques urbanos e uma grande concentração de pássaros (SMAM, 2014). Embora seja considerada uma capital verde e sua população se preocupe com os problemas ambientais, existe um descompasso entre o pensamento, as ações e o comportamento de compra (NASCIMENTO et al., 2011).

Portanto, apesar de haver preocupação com questões ambientais, nem sempre as ações cotidianas são executadas de maneira eco-responsável. Essa contradição entre a forma de pensar e agir pode acontecer devido à falta de conhecimento real sobre o ciclo de vida dos produtos, desde a produção até o seu descarte. Nesse sentido, parece que o consumidor não percebeu a verdadeira dimensão da importância de suas ações quando, por exemplo, faz o descarte dos resíduos incorretamente ou consome um produto nocivo ao meio ambiente.

Tal contradição remete ao termo "alienação", derivado de "alienar", que tem várias definições, entre elas, a de "transferir para domínio alheio" e "cessão de bens". Alienação também pode significar estar alheio, distante. Neste artigo, o termo "alienação" será utilizado para descrever o ato de transferir algo para alguém, sem o conhecimento dos próximos passos ou das consequências dessa transferência.

Na literatura, não foram identificados estudos que discutem a "alienação no descarte" de produtos e embalagens. Desse modo, questiona-se: que fatores estão envolvidos na alienação relacionada ao descarte de produtos e embalagens? Visando responder essa questão e atender ao objetivo de identificar a percepção das pessoas sobre as implicações do ato de descartar um produto ou uma embalagem, foi realizado um estudo exploratório. Para isso, realizaram-se entrevistas em profundidade, semiestruturadas, com cidadãos e especialistas na área socioambiental na cidade de Porto Alegre, Rio Grande do Sul, Brasil.

A temática do descarte de resíduos e do processo de reciclagem é abordada, neste estudo, de forma inovadora, associando a decisão de compra, o nível de informação sobre o ciclo de vida do produto e o ato de descarte. Os resultados desta investigação poderão subsidiar iniciativas à conscientização socioambiental da população, bem como à elaboração de políticas sobre informações de produtos e responsabilidades dos consumidores. 
A seguir, são descritos conceitos e é realizada uma revisão de literatura sobre os temas abordados neste estudo. Na terceira seção, apresenta-se o método utilizado e, em seguida, procede-se à descrição e análise dos resultados. Posteriormente, são apresentadas as considerações finais.

\section{DO CONSUMO AO DESCARTE DE PRODUTOS E EMBA- LAGENS}

Os achados de Minton e Rose (1997) ratificam os resultados dos trabalhos de Schwartz (1977) e Hopper e Nielsen (1991) (apud MINTON; ROSE, 1997), de que os valores pessoais influenciam o comportamento ambientalmente correto e são influenciados pelos valores da sociedade na qual o indivíduo está inserido. Minton e Rose (1997) ressaltam, também, a diferença entre intenção comportamental e comportamento, o que significa que a pessoa pode ter a intenção de ter um comportamento ambientalmente correto, mas não colocá-lo em prática.

Buchholz e Rosenthal (2006) destacam o papel ativo das pessoas na sociedade, já que estas são sujeitos que interferem no meio onde vivem, sofrem e realizam ajustes de diversas ordens, influenciando, também, o contexto institucional. Assim, os consumidores estão preocupados com os valores morais, prestam atenção em empresas que os apóiam e estão mais dispostos a comprar produtos que contenham algum apelo ético (FERRAN; GRUNERT, 2007). Essas atitudes induzem o cidadão a buscar, conscientemente, a redução do impacto negativo de suas ações, bem como minimizar o consumo de energia e recursos, usar substâncias não tóxicas e diminuir a geração de resíduos (Kollmuss; Agyeman, 2002).

Entretanto, conforme Freitas, Rezende e Sediyama (2012), para que haja estímulo ao consumo consciente é necessário considerar o perfil dos consumidores, levando em conta, entre outros aspectos, faixa etária, uso de mídia e estado civil:

[...] jovens solteiros demonstram descrença na mídia, barganham mais em função de menor renda e delegam ao Estado a responsabilidade de promoção do bem estar social, enquanto adultos e idosos casados mostram-se mais conscientes e dispostos a descartar o lixo de modo adequado, evitar o desperdício de água e energia para redução de gastos domésticos, a preservar bens públicos e apoiar movimentos sociais (FREITAS, REZENDE; SEDIYAMA, 2012, p.42).

Constata-se, assim, que o estudo do Comportamento do Consumidor é complexo, pois envolve conhecimentos da área de Psicologia, Antropologia e Sociologia, entre outras. Devem ser consideradas, ainda, atividades físicas, emocionais e mentais do ser humano, o que exige do pesquisador habilidades específicas para o entendimento do fenômeno em evidência. Faz-se necessário ter clareza epistemológica a respeito das diversas possibilidades de estudar as ações humanas, tendo em vista que se trata de seres que consomem por distintas razões e em um contexto multidisciplinar. Em outras palavras, a compreensão da sociedade contemporânea perpassa, consideravelmente, pelo estudo e pelos conhecimentos vinculados ao consumo.

Os consumidores podem expressar seus sentimentos de responsabilidade com relação à sociedade e seu apreço pelas empresas e pelos produtos "responsáveis" por meio de um comportamento de consumo ético. Os consumidores que levam isso em conta veem uma ligação direta entre o seu comportamento de compra e os problemas éticos relacionados, podendo, assim, exercer pressão sobre as empresas (DE PELSMACKER; JANSSENS, 2007).

Os autores Solomon (1999) e Peter e Olson (1999) apresentaram um modelo básico 
de decisão de compra do consumidor que envolve as etapas de: reconhecimento do problema; busca de informação; avaliação de alternativas; compra; e pós-compra. De acordo com Peter e Olson (1999), a natureza desse processo decisório envolve as (i) opções de compra (o que, quando, onde comprar e como pagar), (ii) opções de consumo (consumir ou não, quando e como consumir) e (iii) opções de descarte (descarte ou reciclagem). Engel, Blackwell e Miniard (2000) também adicionam ao modelo tradicional as etapas de consumo e descarte, que seriam as últimas do processo decisório do consumidor.

São essencialmente essas duas últimas etapas que são tratadas na presente investigação, já que a estas pode-se relacionar o conceito de "consumo responsável", o qual é caracterizado pelos consumidores cujas decisões de compra têm sido claramente influenciadas pelo aumento da sensibilidade e da consciência ambiental (Drumwright, 1994; Menon; MENON, 1997). Assim, o consumidor consciente é aquele que leva em consideração as consequências do seu consumo, podendo alcançar mudanças sociais a partir do seu poder de compra.

Portanto, é importante estudar não só quem conduz a decisão de compra como quem realiza o descarte dos resíduos. Conforme Miafodzyeva, Brandt e Olsson (2010), para incentivar o comportamento das pessoas para boas maneiras de reciclagem, é necessário entender o tipo de comportamento que leva a este ato. Os autores realizaram estudo para identificar se o comportamento pré-reciclagem em casa pode ajudar no processo de reciclagem. Os resultados apontam que nem todos os cidadãos estão dispostos a fazer a separação diária de seus resíduos. Para os que responderam que não separavam o lixo, algumas das principais justificativas foram: "eu não tenho tempo para separar, coletar e transportar meu lixo"; "eu não tenho muito espaço no meu apartamento para separar e coletar o lixo"; e "tenho medo de odores desagradáveis". Assim, as razões para não separar são: necessidades de um esforço extra, de mais tempo despendido, problemas de espaço e exigência de transportar o lixo para fora (MIAFODZYEVA; BRANDT; OLSSON, 2010).

Em contrapartida, Kollmuss e Agyeman (2002) afirmam que a chamada orientação egoísta do indivíduo pode ser justamente um motivador para o comportamento pró-ambiental, desde que a ação satisfaça as suas necessidades pessoais (por exemplo, usar trem ao invés de carro, pois o sujeito quer tempo para relaxar e ler). Em estudo com consumidores da cidade de Porto Alegre, Nascimento et al. (2011) observaram que, embora os indivíduos se considerem socioambientalmente responsáveis, as ações praticadas se restringem a atitudes individuais nas suas residências. Os cidadãos não possuem uma visão sistêmica, não percebendo que as suas atitudes podem influenciar toda a cadeia de valor envolvida, a qual descreve o conjunto total de atividades que gera um produto/serviço final, desde sua concepção até seu consumo, descarte e retorno (KAPLINSKY, 2004).

Christopher (2007) destaca a necessidade de uma visão sistêmica da cadeia, em que cada ator que realizar uma ação deve saber que atingirá a cadeia como um todo. Segundo o autor, uma cadeia de suprimentos é constituída de organizações conectadas e interdependentes, que devem trabalhar conjuntamente, em regime de cooperação mútua, para controlar, gerenciar e aperfeiçoar o fluxo de matérias-primas (CRISTOPHER, 2007). A Figura 01 ilustra o fato de que os consumidores, por meio de suas escolhas, podem influenciar a cadeia como um todo. 


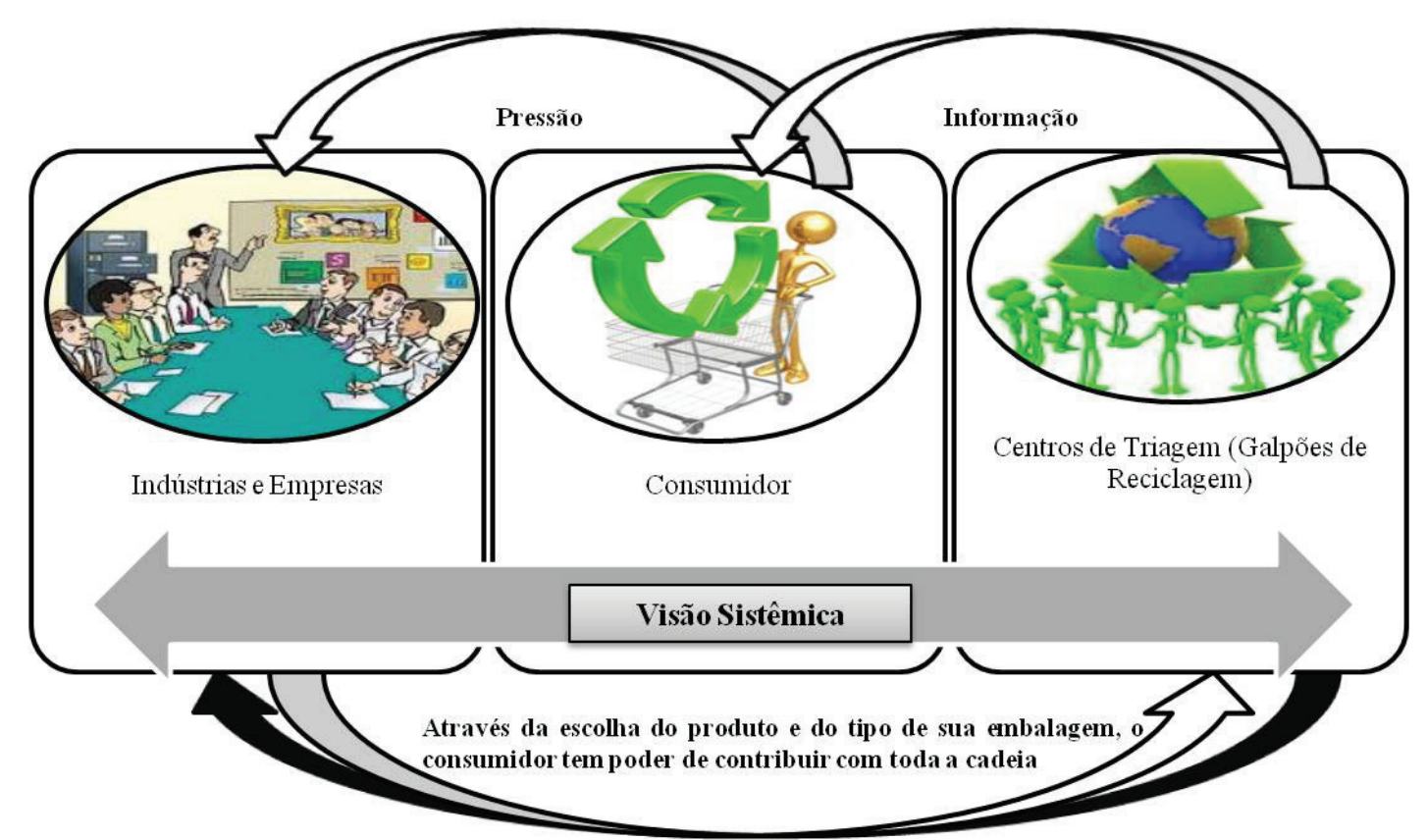

Figura 01: Pressão e poder dos consumidores e necessidade de visão sistêmica da cadeia Fonte: elaborado pelos autores.

Nesse sentido, é relevante destacar alguns resultados encontrados em uma recente pesquisa realizada com 390 unidades domiciliares urbanas do município de Marau, RS, cuja população é de 33.720 habitantes (DAL PIAZ; FERREIRA, 2011). Entre outros objetivos, os autores investigaram as atitudes e os comportamentos dos moradores diante da gestão dos resíduos gerados em suas residências. Os achados apontam "a necessidade de melhorar a gestão pública, o sistema de comunicação, intensificar as ações da gestão pública focando o processo de educação para com o lixo e o meio ambiente, de proporcionar o desenvolvimento da consciência e o conhecimento do gerador" (DAL PIAZ; FERREIRA, 2011, p. 12). Embora seja uma cidade de pequeno porte, já enfrenta desafios para gerenciar eficazmente seus resíduos sólidos urbanos. Os dados a seguir ilustram algumas dificuldades: $84,62 \%$ não souberam informar a frequência (dias e horários) da coleta seletiva ou não responderam ao questionamento; $64,83 \%$ sentem-se frustrados, tendo em vista que separam o lixo em suas casas, mas observam que a coleta é realizada em conjunto (misturando o lixo orgânico com o reciclável) e $20 \%$ não sabem qual o destino dado aos resíduos (DAL PIAZ; FERREIRA, 2011). Acrescenta-se que $42,04 \%$ dos cidadãos que realizam a separação do lixo afirmaram que se sentem incentivados pelas campanhas publicitárias (rádio/TV, material didático, folders). Em síntese, Dal Piaz e Ferreira (2011) consideraram essencial a existência de "sintonia das ações, bom canal de comunicação, avaliação da gestão, planejamento de ações e alinhamento de informações para proporcionar a melhoria contínua na gestão dos resíduos sólidos domiciliares urbanos".

Em Porto Alegre, cidade onde foi realizada a pesquisa, a coleta seletiva iniciou em 1990. Em 2011, após 22 anos de implantação, eram coletadas apenas 100 toneladas desse tipo de resíduo diariamente. Essa coleta é feita por 32 caminhões e o material é distribuído para as 18 Unidades de Triagem conveniadas ao Departamento Municipal de Limpeza Urbana (DMLU), onde trabalham cerca de 750 pessoas, das quais $80 \%$ são mulheres. O rendimento médio mensal desses trabalhadores é de $R \$ 600,00$ (DMLU, 2011), mas poderia ser maior se a população colaborasse mais com a separação do lixo. De acordo com dados do DMLU, são coletadas 1592 toneladas de resíduos sólidos urbanos por dia, o que significa que o lixo orgânico ainda representa um grande problema ambiental. 
Segundo o Diagnóstico do Manejo de Resíduos Sólidos Urbanos, a coleta seletiva de Porto Alegre, no ano de 2009, recolheu 22.880 toneladas, enquanto a coleta comum foi de 502.144 toneladas. Esses números são representados pelos resíduos domiciliares e públicos provenientes do recolhimento do Serviço de Limpeza Urbana do DMLU e de outros serviços municipais (SNSA, 2011). Portanto, muitas embalagens que poderiam ser reaproveitadas não voltam à cadeia de consumo, na forma de matéria-prima, pois vão para o aterro sanitário.

Em julho de 2011, a prefeitura de Porto Alegre implantou uma nova estratégia de coleta de resíduos orgânicos em algumas regiões da cidade. Foram instalados contêineres nas vias públicas de bairros centrais para a coleta automatizada de lixo orgânico domiciliar. Essa nova modalidade de recolhimento não abrange a coleta seletiva e gerou certa polêmica entre cidadãos e autoridades, conforme será discutido nos resultados. A seguir, são detalhados os procedimentos metodológicos utilizados neste estudo.

\section{PROCEDIMENTOS METODOLÓGICOS}

Visando responder ao questionamento inicial, desenvolveu-se uma pesquisa qualitativa, de caráter exploratório. Tendo em vista a inexistência de estudos tratando a alienação a partir do descarte, a pesquisa exploratória proporciona uma maior flexibilidade ao pesquisador na busca de informações sobre determinado fenômeno, a fim de torná-lo mais claro e possibilitar a construção de novas ideias sobre o tema (MALHOTRA, 2006). A abordagem qualitativa foi utilizada com o intuito de aprofundar a riqueza interpretativa, a contextualização do ambiente, os detalhes e as experiências únicas (SAMPIERI; LUCIO; COLLADO, 2006).

Foram realizadas entrevistas em profundidade a partir de um roteiro semiestruturado com seis cidadãos e seis especialistas na área socioambiental, entre os meses de julho e agosto de 2011, na cidade de Porto Alegre, Rio Grande do Sul, Brasil. Os cidadãos foram selecionados levando em conta suas diferenças de idade, gênero e formação, visando contemplar diferentes perfis e percepções acerca da temática. A escolha dos especialistas, por sua vez, visou contemplar distintas áreas de conhecimento (técnicas e de gestão) e profissionais envolvidos diretamente com questões ligadas ao assunto.

A amostra dos doze entrevistados não é representativa dos extratos da sociedade local, mas foi definida com o intuito de captar diferentes opiniões sobre o tema investigado. Foram entrevistadas oito mulheres e quatro homens, com idade variando entre 27 e 64 anos. 0 Quadro 1 traz o código e a profissão dos respondentes.

\begin{tabular}{|c|c|c|}
\hline \multicolumn{2}{|c|}{ Código } & Profissão \\
\hline \multirow{6}{*}{ 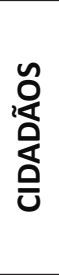 } & $\mathrm{C} 1$ & Funcionária pública \\
\hline & $\mathrm{C} 2$ & Estudante de pós-graduação \\
\hline & $\mathrm{C} 3$ & Vigilante \\
\hline & $\mathrm{C} 4$ & Nutricionista \\
\hline & $\mathrm{C} 5$ & Professora aposentada \\
\hline & $\mathrm{C} 6$ & Analista de Sistemas \\
\hline \multirow{6}{*}{ 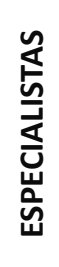 } & E1 & Técnica da Secretaria Municipal do Meio Ambiente \\
\hline & E2 & Pesquisador de uma Universidade \\
\hline & E3 & Líder de ONG ambientalista \\
\hline & E4 & Jornalista especializada no tema \\
\hline & E5 & Coordenador de gestão ambiental de uma Universidade \\
\hline & E6 & Líder de associação de catadores e recicladores \\
\hline
\end{tabular}

Quadro 1: Caracterização dos Entrevistados 
As entrevistas foram gravadas e transcritas, tendo duração entre 35 e 75 minutos. Para tanto, foram elaborados dois roteiros, um para cada grupo de entrevistados, construídos a partir de uma ampla revisão de literatura. A diferença essencial entre os roteiros foi que aos cidadãos foi solicitado que respondessem às perguntas, primordialmente, de acordo com a sua própria conduta; já aos especialistas questionou-se sobre as ações das pessoas de modo geral. Para o tratamento e a interpretação dos dados, foram elaboradas categorias analíticas a partir do referencial teórico abordado e do roteiro de entrevista, conforme o Quadro 2.

\begin{tabular}{|l|l|l|}
\hline \multicolumn{1}{|c|}{ Categorias } & \multicolumn{1}{|c|}{ Descrição } & \multicolumn{1}{|c|}{ Principais autores } \\
\hline $\begin{array}{l}\text { Questões gerais: } \\
\text { meio ambiente e } \\
\text { consciência } \\
\text { ambiental }\end{array}$ & $\begin{array}{l}\text { Percepção acerca dos problemas socioam- } \\
\text { bientais; reação diante de determinadas si- } \\
\text { tuações; água, energia e transporte; grau de } \\
\text { conscientização ambiental. }\end{array}$ & $\begin{array}{l}\text { Minton e Rose (1997); } \\
\text { Jansson, Marell e Nordlund (2010). }\end{array}$ \\
\hline $\begin{array}{l}\text { Comportamento } \\
\text { de compra }\end{array}$ & $\begin{array}{l}\text { Aspectos relevantes na decisão de compra, } \\
\text { informações contidas em rótulos de produ- } \\
\text { tos e poder do consumidor. }\end{array}$ & $\begin{array}{l}\text { Drumwright (1994); Menon e Me- } \\
\text { non (1997); Peter e Olson (1999); } \\
\text { Engel, Blackwell e Miniard (2000); } \\
\text { De Pelsmacker e Janssens (2007). }\end{array}$ \\
\hline Hábitos e atitudes & $\begin{array}{l}\text { Questões relacionadas ao descarte e destino } \\
\text { de produtos e embalagens, especialmente } \\
\text { no que tange ao conhecimento sobre esse } \\
\text { assunto. }\end{array}$ & $\begin{array}{l}\text { Jansson, Marell e Nordlund (2010); } \\
\text { Dal Piaz e Ferreira (2011); Miafo- } \\
\text { dzyeva, Brandt e Olsson } \\
\text { Kaplinsky (2004). }\end{array}$ \\
\hline
\end{tabular}

Quadro 2: Categorias de Análise

\section{DESCRIÇÃO E ANÁLISE DOS RESULTADOS}

A descrição e a análise dos resultados estão estruturadas a partir dos temas abordados nas entrevistas (categorias analíticas): consciência ambiental; comportamento de compra; e hábitos e atitudes relacionados ao descarte de produtos e embalagens.

\subsection{Consciência ambiental}

Inicialmente, as entrevistas foram conduzidas no sentido de captar a opinião dos entrevistados sobre os aspectos socioambientais de modo geral, além de possíveis alterações percebidas na conscientização da população local.

Na percepção do coordenador de gestão ambiental de uma universidade (E5) e da jornalista (E4), as preocupações com as questões socioambientais da população de Porto Alegre aumentaram nos últimos anos. A técnica da Secretaria Municipal de Meio Ambiente (E1) faz um contraponto, salientando que essa temática está tendo muita visibilidade, mas falta ainda inclúi-la no cotidiano das pessoas. Tal opinião é ratificada no depoimento do pesquisador da universidade (E2):

Existe uma distância ainda grande entre o discurso e a prática, ou seja, independente do grau de instrução e da classe social, as pessoas estão informadas e concordam com a importância de cuidar do meio ambiente. [...] Ninguém é contra proteger o meio ambiente [...] mas as pessoas não querem mudar seus hábitos para reduzir seus impactos ambientais.

Os comentários do entrevistado E2 corroboram com os achados de Minton e Rose (1997). Mesmo o consumidor tendo a intenção de comprar um produto ecológico, fatores como preço e qualidade podem fazê-lo desistir. Por outro lado, pode ocorrer de o consumidor ter a intenção de obter informações confiáveis sobre o ciclo de vida do produto que está comprando e não conseguir obtê-las. 
A líder da ONG ambientalista (E3) defende a necessidade de informar as pessoas sobre os seus impactos junto ao meio ambiente, reforçando a importância da visão sistêmica, salientada por Christopher (2007), e também da ação de cada elo para o todo (Figura 1). Sugere que sejam produzidos vídeos criativos, mostrando os caminhos do lixo orgânico e seco, coletando depoimentos dos catadores de rua, de modo a sensibilizar a população em relação ao descarte.

Conforme Jansson, Marell e Nordlund (2010), enquanto as normas, as crenças e os valores pessoais têm significativa influência positiva sobre a disposição para os comportamentos, a força do hábito pode oferecer uma interferência negativa. Para os autores, é considerável o desafio de superar hábitos antigos, adotando novas formas sustentáveis de agir.

De modo geral, os cidadãos entrevistados reconhecem a importância dos cuidados ambientais e concordam que a população local está se conscientizando sobre questões como a separação do lixo. O estudante de pós-graduação (C2) apresenta um posicionamento lúcido em relação à educação ambiental, ao afirmar:

Eu não promovo a educação ambiental, [...] mas não jogo lixo em rio, não jogo lixo no chão. Tento ser educado, mas acho que não sou ambientalmente educado. Acho que só educado mesmo.

A funcionária pública (C1) destacou que conhece pessoas que procuram fazer uso racional e consciente da água e da energia elétrica por questões financeiras e não ambientais. Em geral, são indivíduos humildes, com poucos conhecimentos e recursos. Referindo-se à educação, a entrevistada aponta que "ainda faltam aspectos mais básicos para que essas pessoas comecem a ter consciência ambiental" ( $\mathrm{C} 1$ ) e não ajam levando em conta apenas suas condições financeiras.

A professora aposentada (C5) acredita que atitudes em desacordo com os princípios de preservação ambiental exigem ações severas das autoridades e também da população. Conforme a entrevistada, comportamentos que impactam na sanidade do planeta comprometem a vida e a saúde de cada indivíduo (C5). A funcionária pública (C1) ratifica esse pensamento ao defender que a questão ambiental trata da vida como um todo e não apenas de um momento.

Compreendendo-se as atitudes e os comportamentos dos consumidores em relação ao meio ambiente, é possível promover transformações no modo de produzir, informar, legislar e consumir, favorecendo a substituição de hábitos antigos por novos, ambientalmente adequados. Com base nos depoimentos, percebe-se a existência de dificuldades para abandonar a inércia vinculada a pensamentos e ideias que motivem ações capazes de alterar o espaço em que se vive. Prevalece a transferência de iniciativas e responsabilidades sustentáveis aos outros, ignorando que as consequências afetam a todos.

\subsection{Comportamento de compra}

De maneira geral, o "consumo responsável", caracterizado pelos consumidores cujas decisões de compra têm sido claramente influenciadas pelo aumento da sensibilidade e da consciência ambiental (Drumwright, 1994; Menon; MENON, 1997), não se fez significativamente presente na fala dos entrevistados, principalmente entre os cidadãos. Questionados sobre os critérios utilizados para decidir acerca da compra de um produto no supermercado, o preço continua sendo apontado como o principal fator. Apesar disso, a nutricionista (C4), o estudante (C2), a funcionária pública (C1) e o vigilante (C3) comentaram que, além do preço, costumam observar a qualidade e a validade do produto, bem como a marca (nome da empresa).

Em contrapartida e ao encontro dos estudos de Peter e Olson (1999) e Engel, Blackwell 
e Miniard (2000), o coordenador da gestão ambiental de uma universidade (E5) manifestou que existe uma faixa da população que já considera as questões ambientais na sua decisão de compra. A jornalista (E4), por sua vez, destaca que "o consumidor tem que enxergar outra vantagem além da questão ambiental, que isoladamente não é o fator decisivo na hora da compra". A líder da associação de catadores e recicladores vai além (E6): "Isso [as questões ambientais] o pessoal nem olha. Tem algumas empresas que fazem marketing em cima disso, mas não acredito que alguém vai dizer - 'não, eu tô comprando este produto porque é ecologicamente correto".

Com relação aos rótulos de embalagens, os entrevistados C1, C3, C4, C5 e C6 mencionaram algumas limitações, tais como: letra pequena, validade e fidedignidade das informações e falta de clareza nas informações e nos símbolos. Segundo os especialistas, essas limitações podem levar o consumidor a não ler os rótulos dos produtos. Muitas vezes, até mesmo o prazo de validade passa despercebido. Segundo o especialista $E 5$, isso se deve às dificuldades de compreender as informações:

[...] às vezes eu procuro data de validade em algumas embalagens e é uma dificuldade para achar. Normalmente está numa letrinha pequena, às vezes só no relevo, não está impressa. Ou às vezes o prazo de validade é impresso depois da embalagem, então vem impresso em cima do rótulo.

As entrevistadas C1 e C5 mencionam que gostariam de encontrar nos rótulos informações com palavras simples e claras, de fácil entendimento, conforme é possível observar na seguinte fala: "[...] tinha que ser bem acessível a toda a pessoa que vá comprar o produto, dona de casa, funcionário, até criança. Teria que poder distinguir pelo rótulo o que é poluente do que não é poluente. Ou o que é mais poluente ou menos poluente" (C5).

A especialista E4 considera que a questão dos rótulos também envolve um aspecto cultural e que deveria haver "um trabalho de educação, de ensinar a ler o rótulo, de ensinar a ver o que se está consumindo". Para a especialista E3, os consumidores possuem pouca clareza ou não sabem o que significam os selos que acompanham os produtos, situação que pôde ser percebida no discurso dos cidadãos entrevistados.

É justamente por meio do conhecimento que os consumidores podem expressar seus sentimentos de responsabilidade com relação à sociedade e seu apreço pelas empresas e pelos produtos "responsáveis". Os consumidores preocupados com esse aspecto percebem uma ligação direta entre o seu comportamento de compra e os problemas éticos relacionados, podendo exercer, desse modo, pressão nas empresas (DE PELSMACKER; JANSSENS, 2007).

Quanto ao poder dos consumidores para obrigar as empresas a terem um comportamento ambientalmente responsável, os especialistas E4 e E5 defendem que o nível de mobilização dos cidadãos ainda é muito baixo, mesmo que sejam respaldados pela força legal, com o código do consumidor e com o apoio do Ministério Público. Conforme a líder da ONG ambientalista (E3), as pessoas possuem poder para tal, mas não o exercem. Por sua vez, a líder da associação de catadores e recicladores (E6) acredita que a Política Nacional de Resíduos Sólidos (PNRS) poderá servir para reduzir o número de embalagens, principalmente das que não são fáceis de reciclar.

A entrevistada E6 acrescenta que as pessoas não levam em consideração as embalagens e o tipo de material com que são produzidas, de modo a pensar em todo o ciclo de vida do produto. Destaca que essa deveria ser uma preocupação também do consumidor, mas principalmente de quem produz esse material:

(...) as bandejinhas de doces, de bolo, não se reciclam mais. A caixa de plástico de ovos, não tem o que fazer com ela. O certo seria o produtor que faz aquela embalagem parar 
de produzir, fazer uma de papel ou plástico mais resistente, que desse para aproveitar na cadeia da reciclagem. Acho que o consumidor não sabe disto, ele compra o produto, a qualidade do produto e não a embalagem.

Nesse sentido, questionada sobre a possibilidade de deixar de comprar um produto ao descobrir que o fabricante está poluindo o meio ambiente ou desrespeitando leis trabalhistas, a entrevistada C6 afirma que ficaria indignada, mas que não deixaria de continuar comprando da empresa, e justifica sua resposta: "[...] deixar de comprar o produto é complicado. Se mudar de marca, não vai saber se a outra empresa está fazendo a mesma coisa, só que não foi divulgado" (C6).

Diante desse mesmo questionamento, $\mathrm{C} 2$ afirmou que não deixaria, imediatamente, de comprar o produto. Esses depoimentos mostram que o consumidor ficará indignado e poderá mudar de marca se souber que uma determinada empresa está desrespeitando as leis trabalhistas ou poluindo o meio ambiente. Entretanto, a troca de marca depende da confiabilidade das informações e da segurança de que a outra empresa não está cometendo os mesmos atos. Tal posicionamento relaciona-se com o exposto por Ferran e Grunert (2007), quando afirmam que os consumidores de hoje estão preocupados com valores morais, prestam atenção em empresas que os apoiam e estão mais dispostos a comprar produtos com apelo ético.

$\mathrm{Na}$ busca por produtos ecológicos, a nutricionista (C4) e a professora (C5) procuram usar produtos em sua forma mais natural possível, evitando ao máximo o uso de conservantes químicos. Fazem isso pensando em sua saúde e também em amenizar a produção de resíduos químicos. A entrevistada $\mathrm{C} 4$, ao saber que alguma empresa está fazendo teste com animais, deixa de adquirir e consumir produtos da marca.

Observa-se que a análise da relação entre o preço e a qualidade de um produto está significativamente presente na tomada de decisão e no comportamento de compra dos entrevistados. Posteriormente a esses fatores é que são considerados os aspectos vinculados às questões socioambientais. A carência de informações precisas, compreensíveis e fidedignas sobre a mercadoria pode ser um dos motivos para tal fato. Assim, ressalta-se a importância de campanhas publicitárias informativas, ratificando os resultados encontrados por Dal Piaz e Ferreira (2011).

\subsection{Hábitos e atitudes relacionadas ao descarte de produtos e embalagens}

Com relação aos hábitos relacionados ao descarte de produtos e embalagens, a professora (C5) afirma que é necessária uma mudança de comportamento das pessoas. Mesmo considerando que é fácil ter em casa dois recipientes para a separação dos resíduos, ela diz que é necessária uma ampla campanha para convencer a população.

As cidadãs $\mathrm{C} 4$ e $\mathrm{C} 5$ informaram que, em seus bairros, poucas pessoas fazem a separação do lixo. Nesse sentido, C1, C3 e C6 concordam que, para ser feito o descarte de forma adequada, será necessário reforçar a educação ambiental, ensinando como as pessoas devem agir e quais as consequências das suas ações. A funcionária pública (C1) e o vigilante (C3) sugerem que a população conheça a realidade de um galpão de reciclagem para entender a importância do correto descarte. Ao comentar sobre uma visita que realizou a um desses locais, C1 afirmou:

Percebi que nos galpões as pessoas trabalham em ambientes muito insalubres: sujos, com muito frio ou calor, dependendo da época. Percebi que uma embalagem gera diversos tipos de resíduos que precisam ser separados. Fiquei pensando no que posso fazer, no meu dia-a-dia, para auxiliar essas pessoas. Eu posso lavar o saco do leite, a lata e tantas outras embalagens para facilitar o trabalho dessas pessoas. Assim, não há contaminação com outros resíduos e alimentos. Faz diferença um pequeno ato que eu faça em minha casa. 
O estudante ( $\mathrm{C} 2$ ) não considera eficiente a coleta seletiva de lixo em Porto Alegre. Ele comparou o sistema de coleta local com o da cidade de Caxias do Sul, no interior do Estado. Para ele, o sistema da capital é confuso, pois falta informação sobre o que pode ou não ser colocado nos contêineres que ficam nas ruas. Para $\mathrm{C} 4$, o serviço é eficiente, o que falta são as pessoas saírem da sua "zona de conforto" e passarem a separar melhor o lixo. Ela (C4), assim como C1, C3 e C5, conhece a destinação que é dada ao lixo; porém, pensa que as pessoas em geral não se preocupam com essa questão. A analista de sistemas (C6) e o estudante (C2) desconhecem o destino que é dado ao lixo após ser coletado em frente às suas residências.

Em termos de informação e conhecimento, constataram-se dúvidas e certa polêmica sobre a necessidade de lavar ou não as embalagens descartadas no lixo seco. Tecnicamente, não é necessário lavar, uma vez que isso será feito pela indústria ao processá-las. Mas, é importante saber que o lixo seco recolhido nas ruas da cidade não vai diretamente para as indústrias recicladoras: ele é destinado para os galpões das associações de catadores e recicladores, onde é feita a triagem desse material. Portanto, se o lixo seco for contaminado com resíduos em decomposição, irá atrair insetos, gerar odores desagradáveis e implicar uma série de problemas para a saúde dos trabalhadores, além de inviabilizar a reciclagem, em alguns casos.

Novamente, as sugestões dos entrevistados coincidem com as recomendações de Dal Piaz e Ferreira (2011, p. 12) a respeito da "necessidade de melhorar a gestão pública, o sistema de comunicação, intensificar as ações da gestão pública focando o processo de educação para com o lixo e o meio ambiente, de proporcionar o desenvolvimento da consciência e o conhecimento do gerador" dos resíduos.

Em geral, os especialistas acreditam que os cidadãos têm consciência de que precisam fazer a separação do lixo, mas nem sempre o fazem da maneira mais correta. Segundo o especialista E5, cerca de $60 \%$ dos moradores já fazem a separação. No entanto, o que falta é eficiência: "saber exatamente o que pode ou não ser reciclado". Isso é muito importante, pois, dependendo do mercado, alguns produtos passam a ser recicláveis ou não: “[...] desde que foi implantada a coleta seletiva em Porto Alegre, em 1990, apareceram novas embalagens, que não existiam [...], algumas que não eram, passaram a ser recicladas" (E5).

Segundo o estudante (C2), o que falta é paciência de esperar pela coleta seletiva, que é feita uma ou duas vezes por semana, conforme o bairro. Ele diz que mistura o lixo por não estar disposto a esperar pelo recolhimento, corroborando a justificativa trazida por Miafodzyeva, Brandt e Olsson (2010) para a não separação: necessidade de um esforço extra e de mais tempo despendido, problema do espaço e exigência de transportar o lixo para fora da residência.

A entrevistada E6 aponta que a falta de espaço para guardar lixo seco nos condomínios é um problema do projeto dos prédios, que não prevê espaço para armazenar adequadamente os resíduos. Pode-se dizer que existe a transferência de responsabilidades e das suas naturais consequências para alguém (alienação) não apenas por parte dos cidadãos consumidores, já que ainda há projetos de prédios que ignoram ou desprezam a necessidade de armazenar o lixo seco por alguns dias nos condomínios.

Os especialistas E4 e E5 concordam com os demais entrevistados que se manifestaram dizendo que boa parte da população desconhece a destinação do lixo. Eles confirmam que os cidadãos não possuem a visão sistêmica, não percebendo que as suas atitudes podem influenciar toda a cadeia de valor envolvida. Esta cadeia descreve o conjunto total de atividades que gera um produto/serviço final, desde sua concepção até seu consumo, descarte e retorno (KAPLINSKY, 2004).

O entrevistado E5 acredita que a divulgação do benefício social da coleta seletiva poderia ser um motivador. Comentou que o processo da coleta seletiva na sua universidade melhorou depois que foi realizada uma capacitação com as pessoas que recolhem os resíduos no estabele- 
cimento de ensino. Durante essa capacitação, foram realizadas palestras e as equipes de limpeza foram levadas para conhecer os galpões de reciclagem e seus trabalhadores. Essas ações criaram um clima de solidariedade entre eles.

A líder da ONG ambientalista (E3) incentivou o desenvolvimento de atividades semelhantes e declarou acreditar nos resultados satisfatórios que tais ações podem resultar. A jornalista (E4) afirmou que a população ainda não percebeu que ela também é responsável pelo descarte e pela destinação correta do lixo. Por isto, faz-se necessário um trabalho para promover a conscientização e para que esta se concretize em ação. Salienta, ainda, que é preciso mudar a linguagem das campanhas educativas, a fim de que a informação chegue às pessoas de maneira mais interessante.

O especialista E5 acrescentou que mesmo pessoas com um bom nível de escolaridade não sabem onde colocar resíduos especiais, como lâmpadas fluorescentes, por exemplo. Por isso, considera que "a informação deve ser uma constante [...], até porque informação precisa de atualização". A entrevistada E1 concorda que, em geral, a população desconhece a destinação que é dada aos resíduos. Nesse sentido, E5 declarou que os cidadãos agem de maneira egoísta. Por exemplo, na sua lixeira individual, eles fazem a separação, pois pensam do seguinte modo: "se alguém pegar alguma coisa errada, sou eu o culpado, então ali eu faço a correta separação". Já nos espaços coletivos, o lixo é descartado de qualquer forma, pois a origem não será identificada.

A jornalista (E4) sugeriu um incentivo ao descarte correto: "tu começas a educar dando alguns prêmios pra quem fizer corretamente" (desconto em supermercado ou farmácias, por exemplo). Citou o posto de combustíveis como um bom lugar para devolver as garrafas: "podes deixar as embalagens no carro e quando parar num posto é só entregar". Tal sugestão vai ao encontro da opinião dos cidadãos que concordam com a necessidade de haver vários locais acessíveis ao descarte.

Finalizando esta seção, o Quadro 3 expõe uma síntese dos resultados obtidos nesta investigação e os vínculos com outros estudos relacionados ao tema em análise.

\begin{tabular}{|c|c|c|}
\hline Categorias & Resultados desta investigação & Autores de outros estudos \\
\hline $\begin{array}{l}\text { Consciên- } \\
\text { cia } \\
\text { ambiental }\end{array}$ & $\begin{array}{l}\text { a) intenção de ter um comportamento ambiental- } \\
\text { mente correto, mas não colocá-lo em prática em } \\
\text { função do preço e da qualidade do produto e/ou por } \\
\text { não obter informações confiáveis; } \\
\text { b) desafio de superar hábitos antigos, adotando no- } \\
\text { vas formas sustentáveis de agir; }\end{array}$ & $\begin{array}{l}\text { Minton e Rose (1997); Jansson, Ma- } \\
\text { rell e Nordlund (2010). }\end{array}$ \\
\hline $\begin{array}{l}\text { Comporta- } \\
\text { mento de } \\
\text { compra }\end{array}$ & $\begin{array}{l}\text { c) decisões de compra influenciadas pela consciência } \\
\text { ambiental não se fizeram presentes nas entrevistas } \\
\text { (principalmente entre os cidadãos); } \\
\text { d) existe preocupação com valores morais e dispo- } \\
\text { sição para comprar produtos que contenham apelo } \\
\text { ético e exercer pressão junto às empresas; }\end{array}$ & $\begin{array}{l}\text { Drumwright (1994); Menon e Menon } \\
\text { (1997); Peter e Olson (1999); Engel, } \\
\text { Blackwell e Miniard (2000); De Pel- } \\
\text { smacker e Janssens (2007); Ferran e } \\
\text { Grunert (2007). }\end{array}$ \\
\hline $\begin{array}{l}\text { Hábitos e } \\
\text { atitudes }\end{array}$ & $\begin{array}{l}\text { e) transferência de responsabilidades e das suas con- } \\
\text { sequências para alguém (alienação); } \\
\text { f) desconhecimento sobre a destinação do lixo (au- } \\
\text { sência de visão sistêmica) e as influências disso em } \\
\text { toda a cadeia de valor envolvida; } \\
\text { g) reforçar a educação ambiental, ensinando como } \\
\text { as pessoas devem agir e quais as consequências das } \\
\text { suas ações. }\end{array}$ & $\begin{array}{l}\text { Kaplinsky (2004); Miafodzyeva, Bran- } \\
\text { dt e Olsson (2010); Dal Piaz e Ferreira } \\
\text { (2011). }\end{array}$ \\
\hline
\end{tabular}

Quadro 3: Síntese dos resultados obtidos e sua relação com os achados de outros autores

Os resultados desta investigação apontam que a conscientização implica uma reflexão que vai além da hora da compra. É necessário dar opções aos cidadãos e instigá-los a pensar na continuação do pós-compra. Não basta uma embalagem ser reciclável se ela não for descartada corretamente para que o seu destino final, de fato, seja a reciclagem. 


\section{CONSIDERAÇÕES FINAIS}

Os resultados obtidos, apesar de não permitirem generalização, trazem evidências de que existe uma preocupação parcial com as implicações do ato de descartar um produto ou uma embalagem. Os depoimentos dos entrevistados possibilitaram uma melhor compreensão sobre o processo de compra e descarte de produtos, destacando a falta de informação e de conscientização da população.

Constatou-se que a falta de conhecimento das pessoas sobre as questões socioambientais pode estar relacionada à ausência de clareza das informações dos produtos. O conhecimento dos consumidores é fundamental para que estes possam assumir o papel de consumidores-cidadãos (DE PELSMACKER; JANSSENS, 2007). A falta de informação representa um aspecto tão relevante que pode ser uma das razões que leva ao problema apontado por Minton e Rose (1997): sobre a intenção não se converter em comportamento.

Os resultados demonstram que os cidadãos reprovam fortemente empresas que atuam de forma ambientalmente incorreta. No entanto, nem sempre trocam de marca, pois desconhecem se as outras empresas não cometem os mesmos erros. Vê-se, portanto, a necessidade de um fluxo de informações constante, de forma que a população possa saber como agir e, ao mesmo tempo, cobrar as ações corretas das demais instâncias da sociedade. Assim, a informação deve ser transmitida com formato e linguagem adequada para permitir o acesso e o entendimento de todos.

Conforme a recomendação de alguns especialistas entrevistados nesta pesquisa e a constatação de estudos anteriores (DE PELSMACKER; JANSSENS, 2007; DAL PIAZ; FERREIRA, 2011), é essencial investir, de forma permanente, em campanhas publicitárias que mostrem os caminhos do lixo orgânico e seco, expondo como ocorrem as etapas do recolhimento à reciclagem, de modo a orientar e sensibilizar a população em relação ao descarte. Mais do que divulgação, esta investigação evidenciou que pode ser eficaz incentivar e oportunizar experiências aos cidadãos, com visitas a galpões de reciclagem e aterros sanitários. Muitas escolas levam seus alunos para visitar empresas visando mostrar como os produtos são fabricados; por que não levar os alunos para visitar centros de triagem de resíduos e empresas recicladoras para saber o que acontece após descartar um produto ou uma embalagem?

Essa ideia é reforçada, pois observou-se que o compromisso do consumidor com os resíduos por ele gerados parece desaparecer no momento em que o lixo deixou a sua residência. A partir de então, ocorre uma transferência de responsabilidade manifestada pelo desconhecimento e pela alienação acerca das consequências do descarte.

Essa alienação e a transferência de responsabilidade podem estar vinculadas ao pagamento da taxa municipal de limpeza urbana e recolhimento do lixo, que concede ao cidadão o direito de pensar que a sua tarefa foi concluída no momento em que o lixo foi recolhido. Vencida esta etapa, para os alienados, a responsabilidade cabe ao setor público, pouco interessando se o caminhão da Prefeitura ou o catador irá levar o que foi descartado ou se um animal rasgou e espalhou os resíduos. Outro fator passível de vinculação com a falta de comprometimento e o comportamento alienado diante do descarte é a procrastinação quanto à mudança de hábitos, já que a pessoa até sabe o que precisa ser feito, mas adia o início das ações necessárias.

A alienação pode, ainda, estar relacionada à falta de uma educação ambiental que apresente o ciclo de vida completo de cada produto. O consumidor, ao comprar, não vislumbra que terá de descartar a embalagem e, dentro de algum tempo, o produto em si. O descarte é visto como o ato de fazer sumir da frente dos olhos, de modo que tudo que é descartado "desaparece", 
mas as pessoas não se questionam sobre o local para onde vão os resíduos nem sobre quais etapas este resíduo passa até chegar ao seu destino final. Percebe-se, assim, que o processo de decisão de compra não abrange todas as etapas descritas por Peter e Olson (1999). Destas, parece que os consumidores se preocupam mais com a primeira etapa (o que, quando e onde comprar e como pagar), menos com a segunda (consumir ou não, quando e como consumir) e praticamente nada com a terceira (descarte ou reciclagem).

A alienação, conforme dito pelos entrevistados, está presente nos projetos dos condomínios, que não planejam espaços para a armazenagem do lixo seco por alguns dias. Da mesma forma, está presente nos atos dos cidadãos que não sabem se devem ou não lavar as embalagens, quais são os materiais recicláveis e para onde remeter os produtos descartados (como lâmpadas fluorescentes). De fato, parece mais fácil transferir responsabilidade quando o assunto é destinação de resíduos. No entanto, é dever do cidadão ter a consciência de que o ciclo continua e o produto não acaba no momento em que os resíduos são descartados na lixeira ou no contêiner.

$\mathrm{Na}$ verdade, a alienação começa durante a compra, momento em que o consumidor deveria se perguntar: que produto comprar? de quem comprar? por que comprar? há excesso de embalagem? a embalagem é facilmente reciclável? o que fazer ao final da sua vida útil? permite upgrades ou facilidades de conserto para aumentar a sua vida útil? o fabricante responsabiliza-se pelo seu recolhimento e reciclagem? Enfim, são várias questões que o consumidor poderia levar em conta para orientar sua decisão de compra. Provavelmente, não teria todas as respostas, mas isso desencadearia um processo de conscientização e busca de mais informações.

É interessante notar, também, que algumas pessoas se preocupam com os produtos que consomem quando isso diz respeito à sua saúde. Por exemplo, procuram adquirir produtos naturais, sem conservantes químicos, pois isso vai afetar diretamente suas vidas. Porém, em geral, as pessoas não percebem que determinadas embalagens e produtos, quando descartados de forma inadequada, podem causar danos para o meio ambiente e para a sua própria saúde, como é o caso do descarte de pilhas, baterias, remédios e produtos tóxicos.

Outra questão, destacada pelo entrevistado E5, refere-se ao "nível de escolaridade versus alienação no descarte". Pelos depoimentos coletados, percebe-se que universitários e doutores não sabem o que fazer na hora de descartar uma lâmpada fluorescente. Isso evidencia a necessidade de informações mais claras sobre os produtos e da conscientização das pessoas em diferentes níveis de escolaridade.

Como estudo futuro sugere-se a realização de pesquisas de caráter quantitativo que incluam um universo mais amplo de pessoas e cidades com o intuito de comparar resultados. Nesse sentido, parece válido estabelecer comparações com municípios que ainda não possuem a coleta seletiva em funcionamento. Recomenda-se, também, a realização de entrevistas com consumidores de outras localidades do Brasil e do exterior. Como principal limitação está o fato de a coleta de dados ter sido realizada apenas com doze pessoas de uma única cidade. Porém, tais aspectos, mesmo que limitadores, também podem ser considerados como fatores positivos do trabalho, já que expõem subsídios para a realização de surveys conforme sugerido. 


\section{REFERÊNCIAS}

BUCHHOLZ, R. A.; ROSENTHAL, S. B. Integrating Ethics All the Way Through: The Issue of Moral Agency Reconsidered. Journal of Business Ethics, v. 66, p. 233-239, 2006.

CHRISTOPHER, M. Logística e gerenciamento da cadeia de suprimentos: criando redes que agregam valor. 2. ed. São Paulo: Cengage Learning, 2007.

DAL PIAZ, J. F.; FERREIRA, G. M. V. Gestão de resíduos sólidos domiciliares urbanos: o caso do município de Marau - RS. Revista de Gestão Social e Ambiental, v. 5, n. 1, p. 33-47, jan./abr., 2011.

DE PELSMACKER, P.; JANSSENS, W. A model for fair trade buying behaviour: The role of perceived quantity and quality of information and of product-specific attitudes. Journal of Business Ethics, v. 75, n. 4, p. 361-380, 2007.

DEPARTAMENTO MUNICIPAL DE LIMPEZA URBANA (DMLU). Coleta seletiva em Porto Alegre completa 21 anos. Disponível em: <http:// www2.portoalegre.rs.gov.br/portal_pmpa_ novo/default.php?p_noticia $=143077 \&$ COLETA+SELETIVA+CHEGA+A+MAIORIDADE+NA+ CAPITAL>. Acesso em: 28 ago. 2011.

DRUMWRIGHT, M. E. Socially responsible organizational buying: environmental concern as a noneconomic buying criterion. Journal of Marketing, v.58, p.1-19, 1994.

ENGEL, J.; BLACKWELL, R. D.; MINIARD, P. W. Comportamento do consumidor. Rio de Janeiro: LTC, 2000.

FERRAN, F.; GRUNERT, K. G. French fair trade coffee buyers' purchasing motives. Food Quality and Preference, v. 18, p. 218-229, 2007.

FREITAS, A. G. G. de; REZENDE, D. C. de; SEDIYAMA A. Padrões de Consumo Consciente: identificando segmentos de mercado. Espacios, v. 33, n. 1, p. 40-42, 2012.
JANSSON, J.; MARELL, A.; NORDLUND, A. Green consumer behavior: determinants of curtailment and eco-innovation adoption. Journal of Consumer Marketing, v. 27, n. 4, p. 358-370, 2010.

KAPLINSKY, R. Spreading the Gains from Globalization - What Can Be Learned from Value-Chain Analysis? Problems of Economic Transition, v. 47, n. 2, p. 74-115, 2004.

Kollmuss, Anja; Agyeman, Julian. Mind the Gap: Why do people act environmentally and what are the barriers to proenvironmental behavior? Environmental Education Research, v.8, n.3, 2002.

MALHOTRA, N. K. Pesquisa de Marketing: uma orientação aplicada. 4a. Porto Alegre: Bookman, 2006.

MENON, A.; MENON, A. Enviropreneurial marketing strategy: the emergence of corporate environmentalism as marketing strategy. Journal of Marketing, v.61, p.51-67, January, 1997.

MIAFODZYEVA, S.; BRANDT, N.; OLSSON, M. Motivation recycling: pre-recycling case study in Minsk, Belarus. Waste Management \& Research, v.28, p. 340-346, 2010.

MINTON, A. P.; ROSE, R. L. The Effects of Environmental Concern on Environmentally Friendly Consumer Behavior: An Exploratory Study. Journal of Business Research, v. 40, p. 37-48, 1997.

NASCIMENTO, L. F. et al. Environmental Awareness, Habits and Expectations for the Future of the City of Porto Alegre", accepted for presentation in a Cross Divisional Paper session at the 2011. In: Academy of Management Meeting, 2011, San Antonio. West Meets East: Enlightening, Balancing, and Transcending, 2011.

PETER, J. P.; OLSON, J. C. Consumer behavior and marketing strategy. Irwin/McGraw-Hill, 1999. 
SAMPIERI, R. H.; COLLADO, C. F.; LUCIO, P. B. Metodologia da Pesquisa. São Paulo: McGrawHill, 2006.

SECRETARIA NACIONAL DE SANEAMENTO AMBIENTAL. Sistema Nacional de Informações sobre Saneamento: diagnóstico do manejo de resíduos sólidos urbanos - 2009. Brasília: M. CIDADES. SNSA, 2011.

SMAM. SECRETARIA MUNICIPAL DO MEIO AMBIENTE DE PORTO ALEGRE. Disponível em: $<$ http://www2.portoalegre.rs.gov.br/smam/ default.php?p_secao=122>. Acesso em: 03 Jun. 2014.

SOLOMON, M. R. Consumer behavior: buying, having, and being. 4 ed. New Jersey: PrenticeHall, 1999. 